\title{
Dyeing performance of cotton fabrics with natural curcuminoid in supercritical carbon dioxide
}

Keywords: chitosan, cotton fabrics, supercritical carbon dioxide, curcuminoid, dyeing

\section{Introduction}

Cotton is used in all types of garments and household fabrics, being used in clothing and hats, carpets and curtains, boots and shoes etc. Now days, chemical dyes are the most widely used dyes for cotton fabric dyeing. ${ }^{1}$ Conventional dyeing of cotton textiles produces large amount of waste waters that must be treated before it can be discharged into the surrounding environment, thus restricts the development of textile industry. ${ }^{2}$

From 1980s, a new process for dyeing textiles using supercritical carbon dioxide instead of water was developed. When compared with conventional wet dyeing processes, supercritical carbon dioxide dyeing processes have many essential advantages, as carbon dioxide is a benign, nonflammable, non-toxic and inexpensive solvent, and its supercritical state is easy to get (the critical point of carbon dioxide is at $31.1^{\circ} \mathrm{C}$ and $7.38 \mathrm{MPa}$ ); in addition, after the dyeing process it can be readily recycled. ${ }^{3}$ Moreover, the energy and timeconsuming dry procedure is also no longer needed as the dyeing process is water free. ${ }^{4}$ Therefore, as an innovational and clean dyeing technology, supercritical carbon dioxide dyeing processes are more environmentally friendly and economically attractive for the textile industry. ${ }^{5}$ To date, the coloration of synthetic fibers, such as polyethylene terephthalate (PET), ${ }^{6}$ polylactides, ${ }^{7}$ polyamide 6 and $66,{ }^{8}$ with disperse dyes in supercritical carbon dioxide has achieved commercial requirements. But it is still difficult for the dyeing of cotton fabrics in supercritical carbon dioxide. The main reason lies in the facts that disperse dyes have low affinity to cotton fibers.

Natural curcuminoid is one of effective components of the thizoma curcumae longae, it's not only used as food additive but also has a unique pharmacological functions. ${ }^{9}$ The curcuminoid has many essential advantages, as good thermal stability, strong tinting strength, safe and non-toxic. There're more than one double bond, phenolic hydroxyl and carbonyl group in the molecular. The chemical structures of curcuminoid are shown in Figure 1.

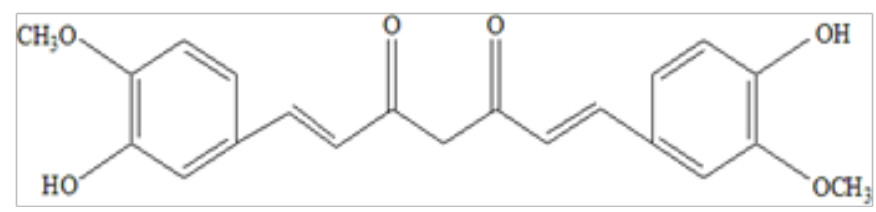

Figure I Chemical structural of curcuminoid.

Hydrogen bond can be formed between cellulose and curcuminoid molecular thus has good affinity between each other.

In the present work, the dyeing of cotton fabrics with natural curcuminoid in supercritical carbon dioxide was studied (Figure 2).

The cotton fabrics were put into the dyeing kettle. The curcuminoid with $10 \%$ o.m.f. (on the mass of fabrics) was added into the dye kettle. Carbon dioxide in the $\mathrm{CO}_{2}$ tank

\author{
Volume 5 Issue 2 - 2019
}

Wei Ju, Fu Wen-xiu

School of Textile \& Material Engineering, Dalian Polytechnic University, China

Correspondence: Wei Ju, School of Textile \& Material Engineering, Dalian Polytechnic University,Dalian I 16034, China, Email|3238056518@|63.com

Received: June 28, 2018 | Published: March 13, 2019

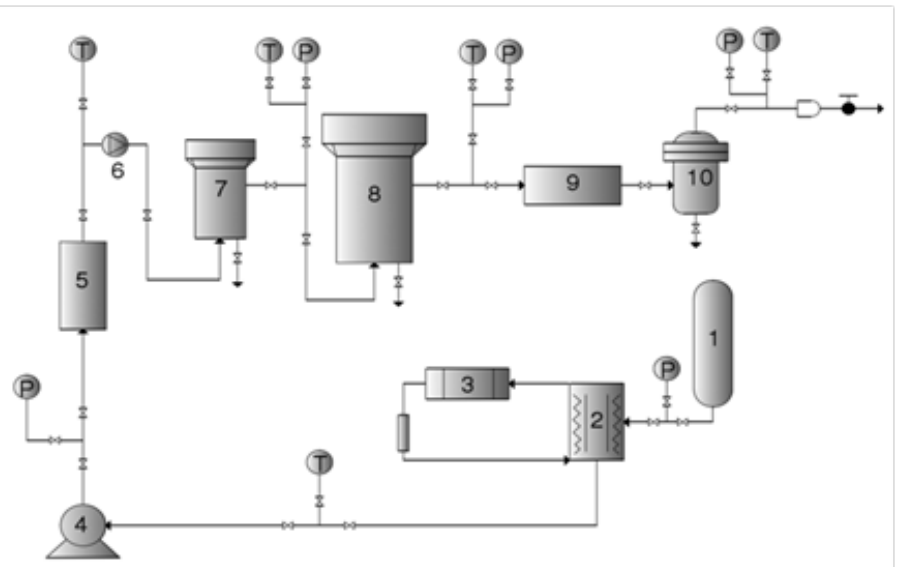

Figure 2 Schematic drawing of the supercritical carbon dioxide dyeing apparatus; (1) $\mathrm{CO}_{2}$ tank, (2) cooling tank, (3) refrigeration units, (4) highpressure pump, (5) heat exchanger, (6) flowmeter (7) dye kettle, (8) dyeing kettle, (9) separator,(I0) separation kettle.

1) was cooled and changed into liquid by cooling tank

2) and refrigeration units

3) It was pressurized using a high-pressure pump

4) and was heated with a heat exchanger

5) First, supercritical carbon dioxide entered the dye kettle

6) the curcuminoid was then dissolved in supercritical carbon dioxide fluid and flowed through the dyeing kettle

7) In which cotton fabrics would be dyed. The dyeing experiments were conducted for 30 minutes at $90^{\circ} \mathrm{C}, 25 \mathrm{MPa}, \mathrm{CO}_{2}$ flow of $30 \mathrm{~g} / \mathrm{min}$. When the dyeing process ended, high-pressure pump and heat exchanger were switched off in turn to reduce the pressure of the system, $\mathrm{CO}_{2}$ and dye in the dyeing system were separated with a separator

8) The residual dye will be kept in the separator

9) $\mathrm{CO}_{2}$ was gasified completely. Finally, the system pressure turned to normal and the dyed fabrics were taken out. 
Cotton fabrics dyed under the above condition got good color, the average $\Delta \mathrm{E}$ is $50.3, \mathrm{~K} / \mathrm{S}$ value is 1.6 . Tenacity of the dyed cotton fabric decreased from 23.4MPa to 21MPa. Cross section of the dyed cotton fabric yarn was shown in Figure 3 which indicates that the supercritical carbon dioxide dyeing process will have some damage on the cotton fabrics but still within the permit range.

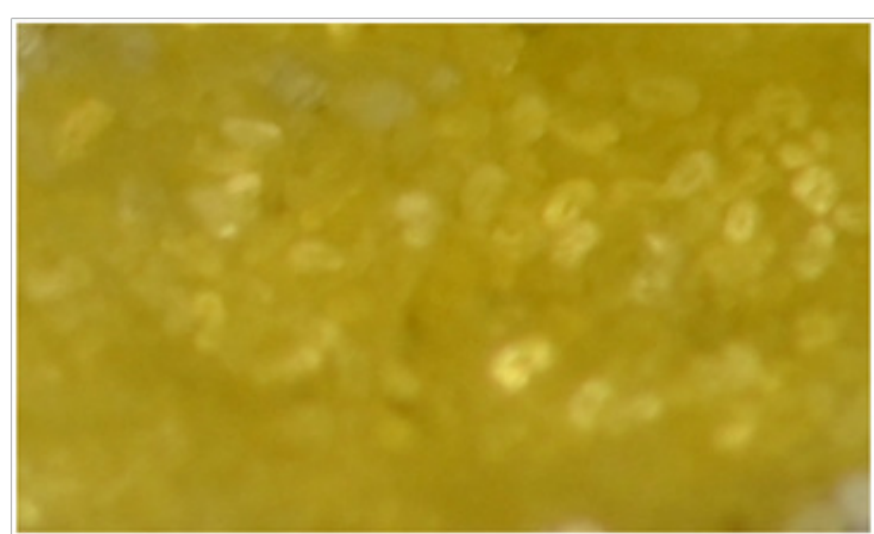

Figure 3 Cross section of the supercritical carbon dioxide dyed cotton fabric yarn.

From Figure 3 we can see that the curcuminoid dye has dispersed in the core of the yarn, which indicates that the supercritical carbon dioxide dyeing technique has the advantage of high penetration. Color of some cotton fiber is deeper and the other is lighter, it can be explained that the crystallinity of the single cotton fiber is different, since the dye molecular can just diffuse into the non-crystalline region, so fibers with lower crystallinity can be dyed into deeper color.

\section{Conclusion}

Cotton fabrics can be dyed by supercritical carbon dioxide technique successfully at temperature of $120^{\circ} \mathrm{C}$, pressure of $25 \mathrm{MPa}$, time of $30 \mathrm{~min}$. The $D E^{*}$ and $K / S$ value of the dyed cotton fabrics are 50.3 and 1.6, respectively. Tensile test showed that the tenacity of the cotton fabrics declined after dyeing but still within the permitted range. The method described in this paper provides a new solution for supercritical carbon dioxide dyeing of cotton fabrics.

\section{Acknowledgments}

None.

\section{Conflicts of interest}

Author declares there is no conflict of interest in publishing the article.

\section{References}

1. Agarwal BJ, Bhattacharya SD. Possibilities of polymeraided dyeing of cotton fabric with reactive dyes at neutral pH. J Appl Polym Sci. 2010;118:1257-1269.

2. Wolfgang S, Knittel D, Schollmeyer E. Dyeing of Textiles in Supercritical Carbon Dioxide. Text Res J. 1993;63(3):135-142.

3. Cabral VF, Santos WLF, Muniz EC, et al. Correlation of dye solubility in supercritical carbon dioxide. J Supercrit Fluids. 2007;40(2):163-169.

4. Banchero M, Ferri A, Manna L, et al. Solubility of disperse dyes in supercritical carbon dioxide and ethanol. Fluid Pase Equilibria. 2006;243(1-2):107-114.

5. Yang MY, Liu J, Zhang YQ, et al. Rope dyeing of fabric in supercritical carbon dioxide for commerical purposes. Coloration Technology. 2014;130(2):102-111.

6. Martijn VDK, Fernandez Cid MV, Woerlee GF, et al. Equilibrium study on the disperse dyeing of polyester textile in supercritical carbon dioxide. Text Res J. 2007;77(8):550-558.

7. Wen HB, Dai JJ. Dyeing of polylactide fibers in supercritical carbon dioxide. J Appl Polym Sci. 2007;105(4):1903-1907.

8. Long J, Xiao GD, Xu HM, et al. Dyeing of cotton fabric with a reactive disperse dye in supercritical carbon dioxide. $J$ Supercrit Fluid. 2012;69:13-20.

9. Angel L, Nélio TM, Marilena EA, et al. Araujo supercritical $\mathrm{CO}_{2}$ extraction of curcumins and essential oil from the rhizomes of turmeric ind. Eng Chem Res. 2000;39(12):4729-4733. 